\title{
Strain rate effects on reinforcing steels in tension
}

\author{
Ezio Cadoni ${ }^{1}$ and Daniele Forni ${ }^{1,2, a}$ \\ ${ }^{1}$ DynaMat Laboratory, University of Applied Sciences of Southern Switzerland, Switzerland \\ ${ }^{2}$ Department of Structural, Geotechnical and Building Engineering, Politecnico di Torino, Italy
}

\begin{abstract}
It is unquestionable the fact that a structural system should be able to fulfil the function for which it was created, without being damaged to an extent disproportionate to the cause of damage. In addition, it is an undeniable fact that in reinforced concrete structures under severe dynamic loadings, both concrete and reinforcing bars are subjected to high strain-rates. Although the behavior of the reinforcing steel under high strain rates is of capital importance in the structural assessment under the abovementioned conditions, only the behaviour of concrete has been widely studied. Due to this lack of data on the reinforcing steel under high strain rates, an experimental program on rebar reinforcing steels under high strain rates in tension is running at the DynaMat Laboratory. In this paper a comparison of the behaviour in a wide range of strain-rates of several types of reinforcing steel in tension is presented. Three reinforcing steels, commonly proposed by the European Standards, are compared: B500A, B500B and B500C. Lastly, an evaluation of the most common constitutive laws is performed.
\end{abstract}

\section{Introduction}

Failure in engineering is understandably considered a negative occurrence, something that should be avoided at almost any cost. But sometimes a component must fail so that the larger system to succeed. This is a challenge for engineers, because they have to design systems and devices having well defined and predictable breaking points. On the other hand, the structural design should avoid that the presence of a human error or in case of deliberate act of terrorism can be the cause of a catastrophic collapse.

For these reasons, in a safe design is of extreme importance to consider all the possible loadings that could lead to failures, which could be caused by dynamic loads due to natural causes, like strong earthquakes, or accidentally caused by impacts or blasts.

Historically, the behaviour of structures under severe dynamic loading has become an important issue in civil engineering during the last decades because of the increasing number of deliberate terroristic attacks. Worldwide interests, renewed after the 9/11 World Trade Centre disaster, and because of the fresh outbreak of terroristic threats on civilian targets, have further increased the need for knowledge in this field [1]. Consequently, the knowledge of the mechanical properties at high strain rates are needed for the assessment of structures against severe dynamic loads.

In particular, for reinforced concrete structures both concrete and rebar properties have to be considered. This because these two materials have a completely different behavior: the concrete is strong enough in compression, but has a very limited strength in the tensile part of the structure, where the reinforcing steel bars are properly used.

In spite of this, the attention of many researchers was focused on this problem, only the dynamic behavior

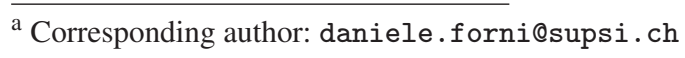

of concrete [2-4] was deeply studied. Consequently, the dynamic behavior of the reinforcing steels remained quite neglected and only few and/or relatively old data were available [5-8].

Malvar [9], considering strain rate tests based on a literature review, proposed a strength enhancement of steel rebar in terms of the dynamic increase factor (DIF). Recently, the new version of the Model Code 2010 [10], has re-adopted the strain rate effect on the reinforcing steel properties based on the CEB Bulletin 187 [4].

In case of high dynamic loadings, high strain rates in the range of $10^{1}$ to $10^{3} \mathrm{~s}^{-1}$ are generated [12-16]. For this reason, new information on the high strain rate behavior of modern rebars is extremely necessary $[13,14]$. According to the current European standards [11], there are three classes of reinforcement, A, B and C, which indicate increasing ductility. In this paper a discussion of the strain rate sensitivity of the main reinforcing steel properties for all three classes B500A, B500B and B500C steels is reported. In the case of B500A and of B500B steel, were used specimens coming from bars having $12 \mathrm{~mm}$ in diameter [14]. While for the B500C steel [17], considered as a composite bar made of a hardened outer cortical layer, an intermediate hardened layer and a soft inner core, the effects of the strain rate on the tensile properties of these three layers were evaluated on specimens coming from a bar having $40 \mathrm{~mm}$ in diameter.

Finally, an evaluation of the most common constitutive laws, such as Johnson-Cook [18] and Cowper and Symonds [19] relationships, were performed.

\section{Experimental procedure}

The dynamic behavior of reinforcing steels was analysed in a wide range of strain rates: quasi-static, intermediate and high strain rates.

This is an Open Access article distributed under the terms of the Creative Commons Attribution License 4.0, which permits unrestricted use, distribution, and reproduction in any medium, provided the original work is properly cited. 


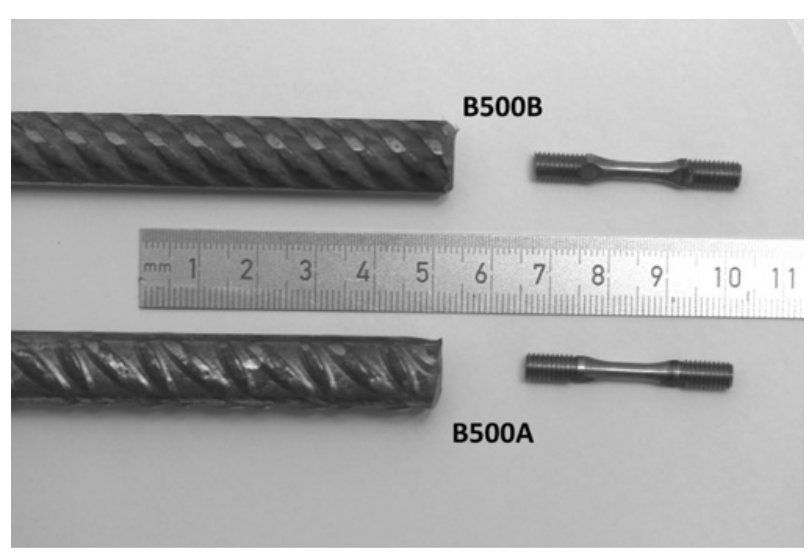

Figure 1. Photo of the B500A and B500B rebar and specimens.

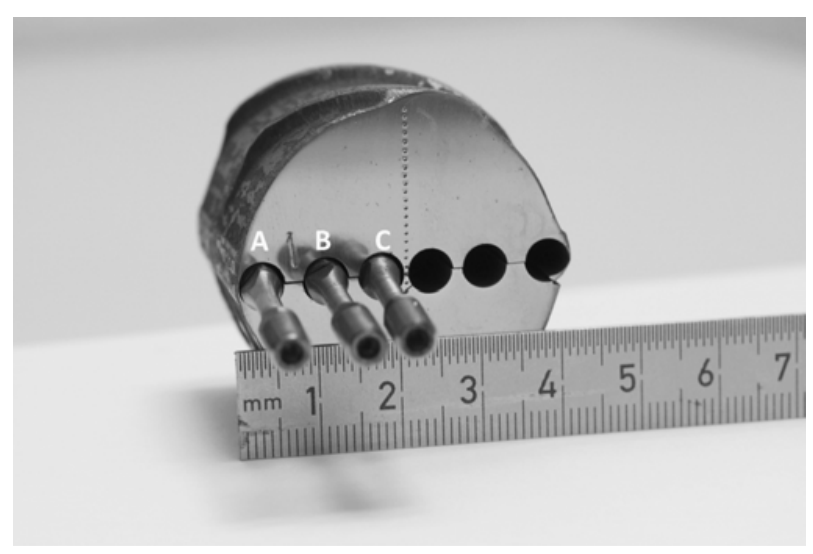

Figure 2. Photo of the B500C rebar and specimens.

The specimens used were cylindrical samples having $5 \mathrm{~mm}$ of gauge length and a diameter of $3 \mathrm{~mm}$ [12-14]. In case of B500A, B500B samples were obtained, from rebars (having a diameter of $12 \mathrm{~mm}$ ), by turning, while for B500C material, samples were firstly extracted from a bar of $40 \mathrm{~mm}$ by means of a wire electrical discharge machine as described in [17] as shown in Fig. 2.

The quasi-static tests were performed at $10^{-3} \mathrm{~s}^{-1}$ by means of a universal electro-mechanical testing machine Zwick/Roell-Z50 with a maximum load bearing capacity of $50 \mathrm{kN}$. The intermediate tensile tests were performed at 5 and $25 \mathrm{~s}^{-1}$ by means of a Hydro-pneumatic machine (HPM), whose functioning was widely explained in [2023]. Three high strain rates 250,500 , and $1000 \mathrm{~s}^{-1}$ were carried out by means of a Split Hopkinson Tensile Bar (SHTB) [12-14].

\section{Results and discussion}

The reinforcing steels were investigated in a wide range of strain rates. The results, in terms of stress versus strain curves, of the tensile tests at the different strain rate are shown in Figs. 5-8. In particular in Fig. 5 are depicted the curves for the B500A steels, while in Fig. 6 the curves for B500B steel are shown. These figures shown how these steels have very high ductility in dynamic regime.

In case of B500C the represented data showed in Figs. 6-8 were obtained by means of the weighted strength

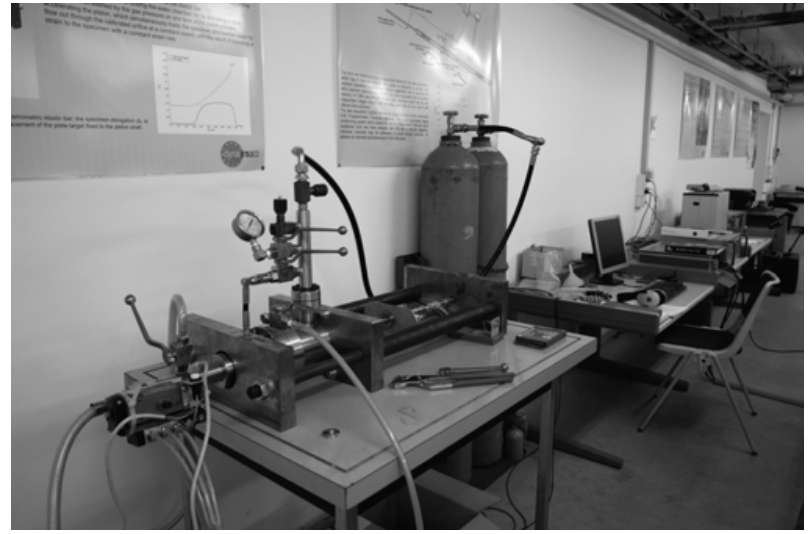

Figure 3. Hydro-Pneumatic Machine for intermediate strain rates tests.

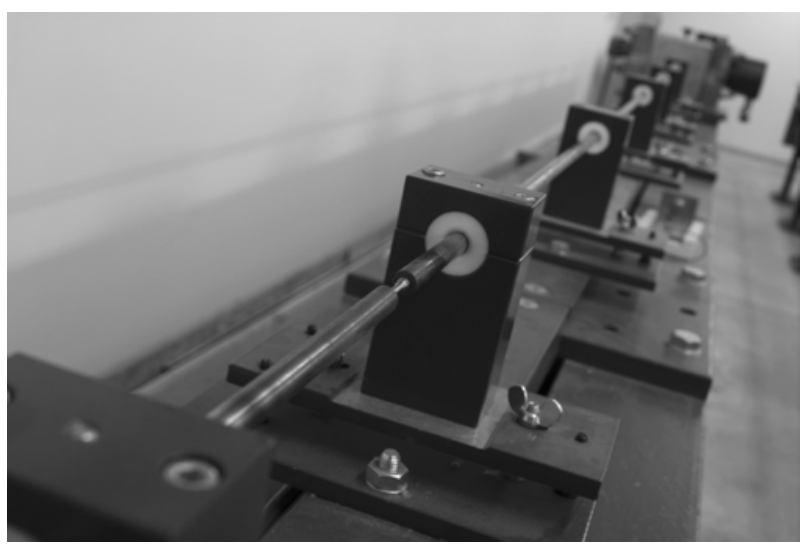

Figure 4. Split Hopkinson Tensile Bar device for high strain rates tests.

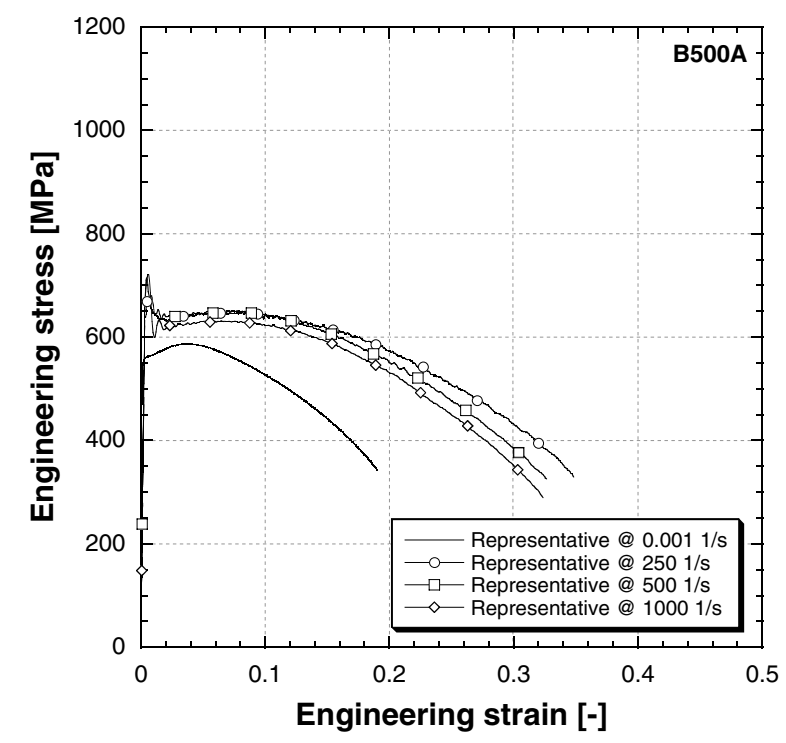

Figure 5. B500A mechanical properties trend versus strain-rate.

values of the three different zones [14] in function of the respective area of the cross section in the rebar. Also in this case the mechanical characteristics increase with the increasing of the strain rate (i.e. ultimate tensile strength as well as the uniform strain). Observing the fracture strain at different strain rate can be noted how this increment 


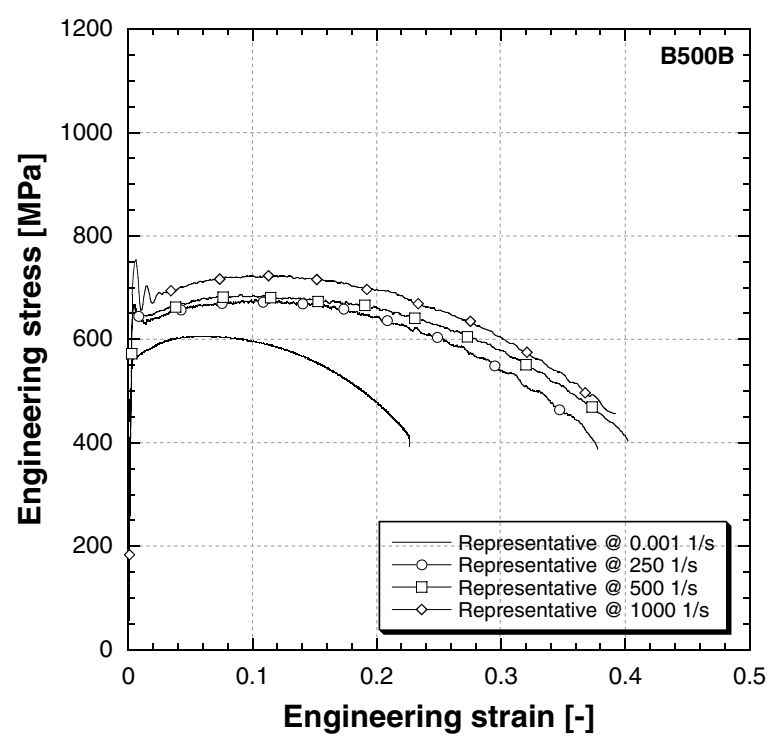

Figure 6. B500B mechanical properties trend versus strain-rate.

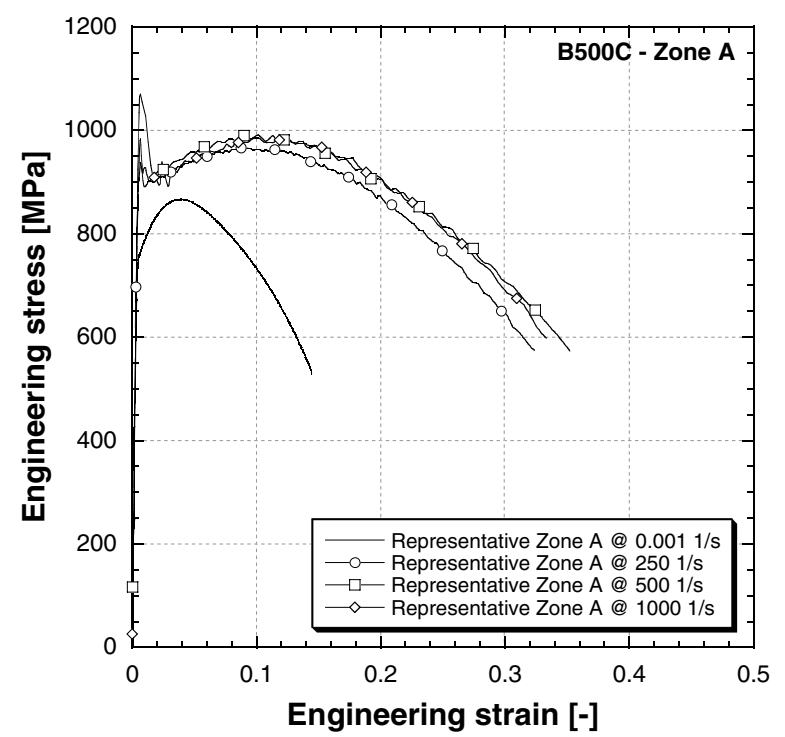

Figure 7. B500C mechanical properties trend versus strain-rate.

becomes larger for the softer material such as the core material in B500C [17].

More information about the evolution of the mechanical parameter of these reinforcing steel can be obtained looking at the Figs. 9-11.

In Fig. 9 a representation of the strain-rate sensitivity of this B500A reinforcing steel is given, with the tendency line of the yield strength and the Ultimate Tensile Strength (UTS) as a function of strain rate and tendency line of the uniform and fracture strain, and the reduction in crosssectional area. For each of these trends, a visual trend line is included to help distinguish the data sets.

The same data were analysed for the B500B reinforcing steel (Fig. 10) and for B500C, as average weighted values (Fig. 11). It is possible to point out that even if the B500C steel is more ductile with respect to the B500A steel in case of static conditions, at higher strain rates this difference is lower. The B500C steel has a pronounced decrease of ductility at high strain rates.

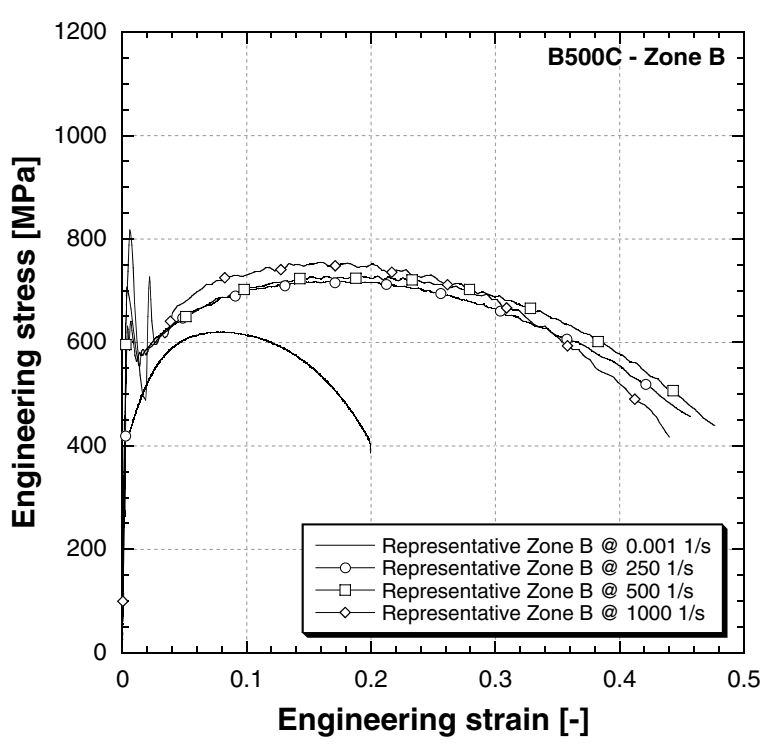

Figure 8. B500C mechanical properties trend versus strain-rate.

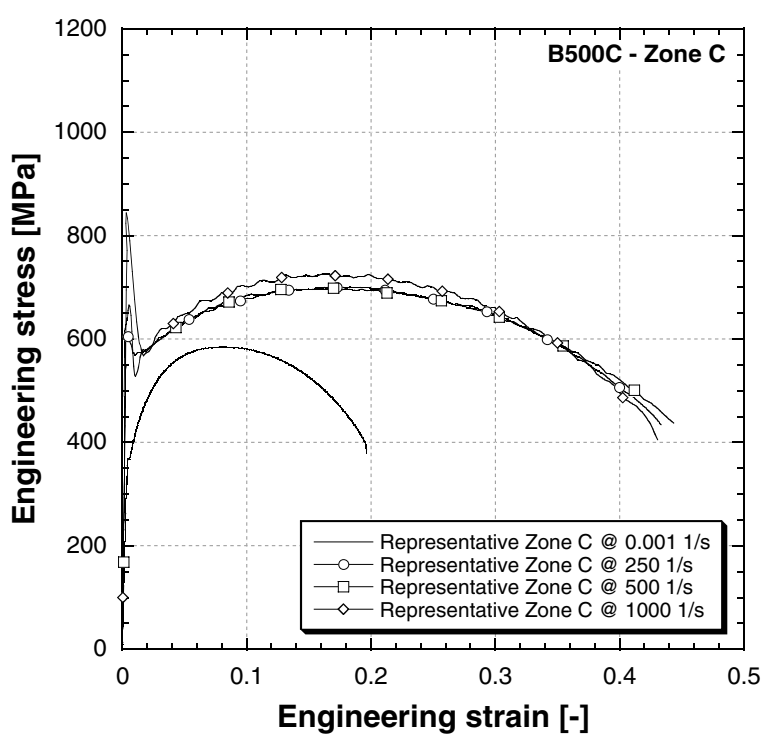

Figure 9. B500C mechanical properties trend versus strain-rate.

A fundamental property for rebar is the ductility that can be measured with the ratio between the UTS and yield stress. This parameter is represented in Fig. 12 for B500A and $\mathrm{B} 500 \mathrm{~B}$ reinforcing steels.

The B500B reinforcing steel shows a constant decrease of the ductility parameter while the B500A reinforcing steel is quite constant for the higher velocities.

\section{Constitutive laws}

The experimental results were used to calibrate two well-known material constitutive relationships such as Johnson-Cook [19] and Cowper-Symonds [20]. These are widely used models. The first is based on three independent phenomena, the isotropic hardening, the strain-rate hardening and the thermal softening.

$$
\sigma_{\mathrm{JC}}=\left(\mathrm{A}+\mathrm{B} \cdot \epsilon_{\mathrm{p}}^{\mathrm{n}}\right) \cdot\left(1+\mathrm{C} \cdot \operatorname{In} \dot{\epsilon}_{\mathrm{p}} / \dot{\epsilon}_{0}\right) \cdot\left(1-\hat{\mathrm{T}}^{\mathrm{m}}\right) .
$$




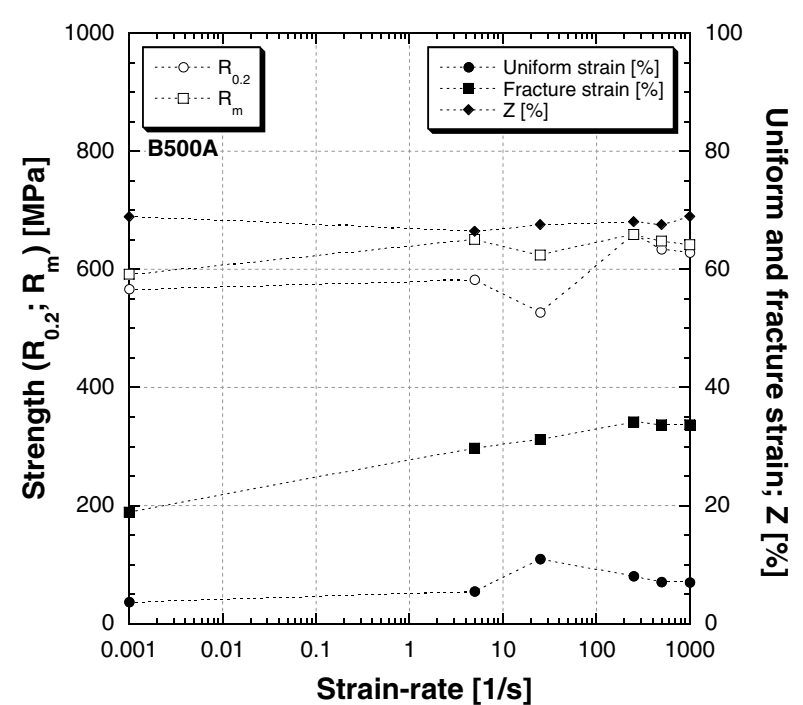

Figure 10. B500A mechanical properties trend versus strain-rate.

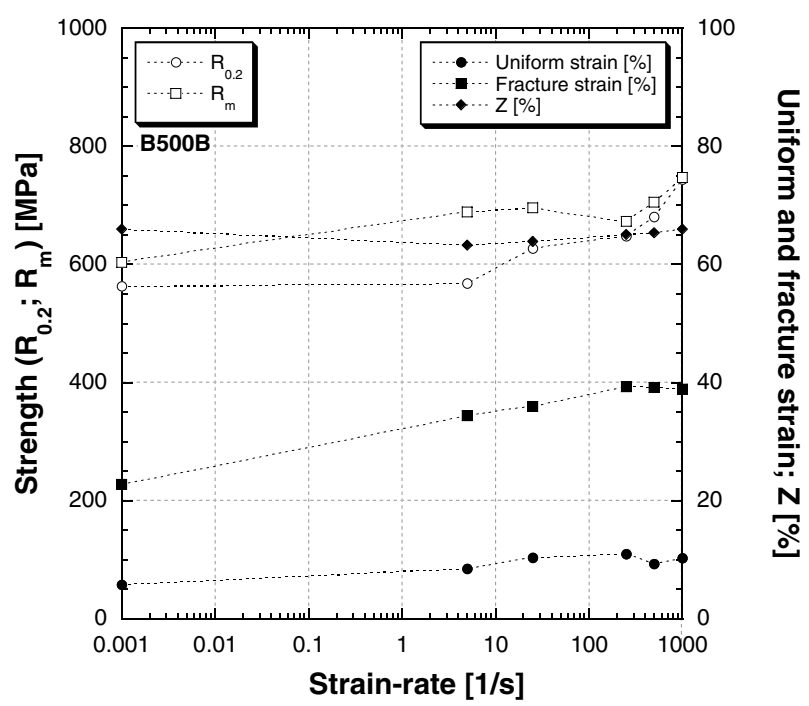

Figure 11. B500B mechanical properties trend versus strain-rate.

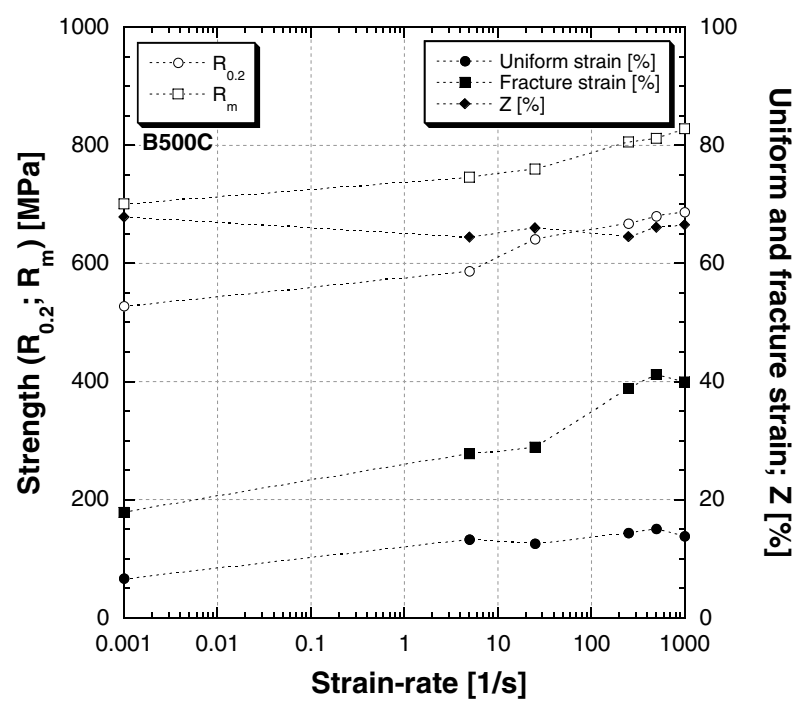

Figure 12. B500C mechanical properties trend versus strain-rate.
Table 1. Johnson-Cook parameters.

\begin{tabular}{|l|l|l|l|l|}
\hline & A & B & $\mathrm{n}$ & $\mathrm{C}$ \\
\cline { 2 - 5 } & {$[\mathrm{MPa}]$} & {$[\mathrm{MPa}]$} & {$[-]$} & {$[-]$} \\
\hline B500A & 564 & 946 & 0.875 & 0.01769 \\
\hline B500B & 571 & 643 & 0.720 & 0.02139 \\
\hline
\end{tabular}

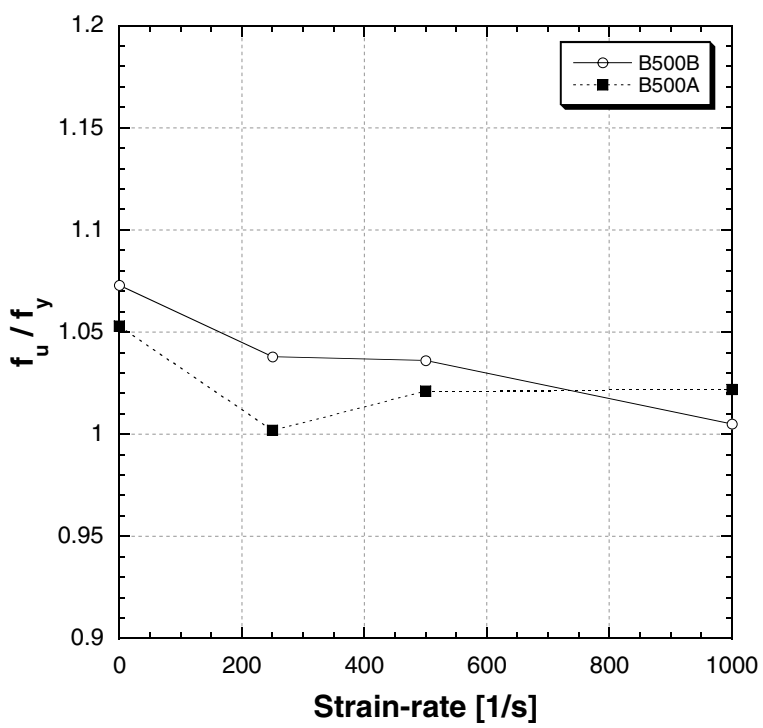

Figure 13. B500C mechanical properties trend versus strain-rate.

Table 2. Cowper-Johnson-Cook parameters.

\begin{tabular}{|l|l|l|}
\hline Material & $\mathrm{D}$ & $\mathrm{q}$ \\
\hline B500A & 141917 & 2.816 \\
\hline B500B & 599 & 0.753 \\
\hline
\end{tabular}

The parameters to be determined from the experimental results are $A, B$, and $n$ in order to take into account the strain-hardening, as well as $C$ and $m$ that represent the strain-rate sensitivity and the thermal softening respectively. In this case, the thermal softening parameter is set equal to one, due to the fact the temperature effect at high strain rates is actually under investigation, and only room temperature tests have been considered. The previously mentioned material parameters are reported in Table 1.

In Fig. 13 the comparison between Johnson-Cook model and experiments are depicted.

The second model is a strain rate dependent elasticplastic model and is able to relate the dynamic stress with the strain rate by means of two constants D and q:

$$
\frac{f_{d}}{f_{0}}=1+\left(\dot{\epsilon_{\mathrm{p}}} / D\right)^{1 / q}
$$

where $f_{d}$ is the dynamic yield true stress, $f_{0}$ is the static yield true stress, $\dot{\epsilon} \mathrm{p}$ is the strain rate, D and $\mathrm{q}$ are material parameters.

In Table 2 the D and q parameters of two reinforcing steel are reported while in Fig. 14 the true yield stresses versus strain rate and the model prevision are shown. 


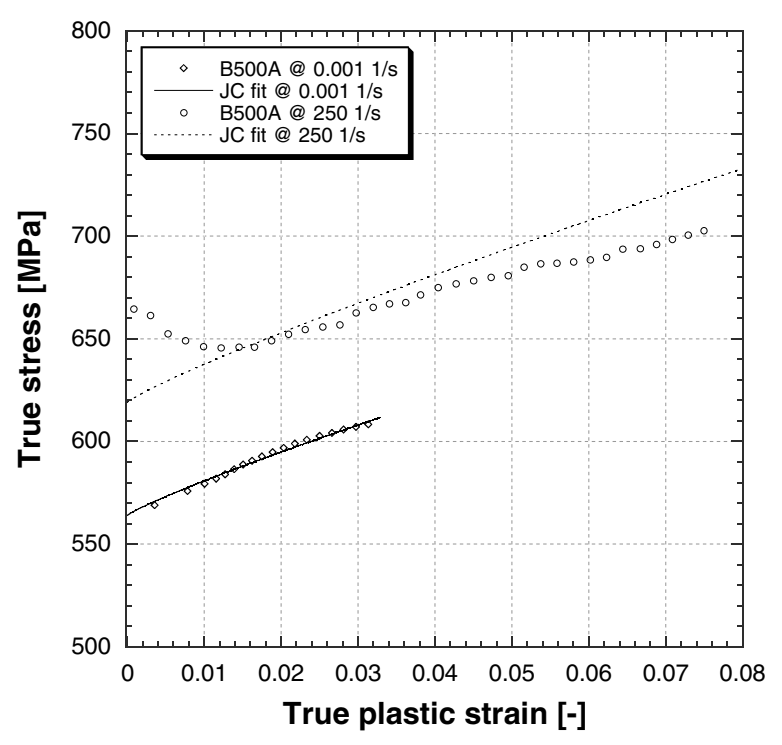

Figure 14. Jonhson-Cook model for B500A steel.

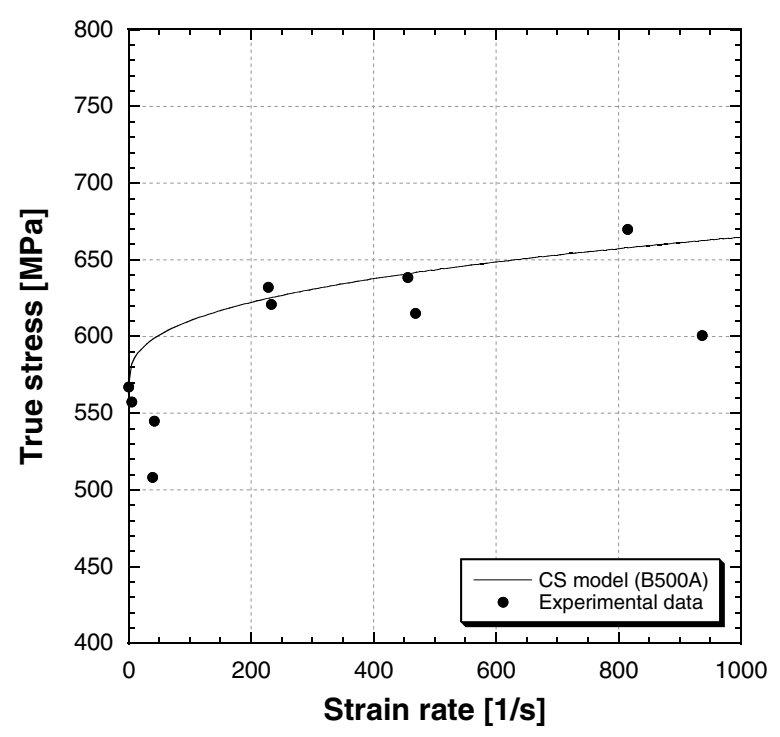

Figure 15. Cowper-Symonds model for B500A steel.

\section{Conclusions}

The strain rate effects on the behaviour of different reinforcing steels in tension were investigated.

The mechanical behaviour of B500A, B500B and B500C reinforcing steel was analysed by two experimental set-ups such as Hydro-Pneumatic Machine and Split Hopkinson Tensile Bar device used respectively for intermediate and high strain rate.

The examined reinforcing steels show high strain rate dependency.

Results on different layers of B500C confirm the fact that this quenched and self-tempered reinforced steel has to be considered as a composite structure. For this reason a special attention should be attended in order to simulate the structural performance of a real rebar subjected to high strain rates [16].

Two widely used material models were calibrated on the basis of the experimental results obtained.
The predicted flow stress by Johnson-Cook model has good agreement with the experimental results.

The parameters search will be concluded with the high strain rate tests in temperature, providing the parameter $\mathrm{m}$ and calibrating other constitutive relationship as ZerilliArmstrong and others.

The authors wish to thank Matteo Dotta and Nicoletta Tesio of the DynaMat Laboratory, University of Applied Sciences of Southern Switzerland, for their help in the experiments. The research was financially supported by the project COST C12.0051 entitled "Behaviour of structural steels under fire in a wide range of strain rates" funded by Swiss State Secretariat of Education, Research and Innovation of the Swiss Confederation in the frame of the COST Action TU0904 "Integrated Fire Engineering and Response".

\section{References}

[1] COST TU0601 - Robustness of Structures: http:// www. cost.eu/COST_Actions/tud/Actions/ TU0601

[2] P.H. Bishoffs, S.H. Perry, Mat. Struct. 24, 425-450 (1991)

[3] L.J. Malvar, C.A. Ross, ACI Mat. J. 95(6), 735-739 (1998)

[4] Comité Euro-International du Béton, Bulletin 187, (1988)

[5] J. Seabold, Tech. Rep. R695, (1970)

[6] W.L. Cowell, Tech. Rep. R394, (1965)

[7] W. Keenan, J. Tancreto, G. Meyers, F. Johnson, J. Hopkins, H. Nickerson, W. Armstrong, Tech. Mem. 51-83-19 (prev. 2591TM), (1983)

[8] R.G. Crum, ACI J. Proc. 56(1), 59-61 (1959)

[9] L.J. Malvar, ACI Mat. J. 95, 609-616 (1998)

[10] FIB-International Federation for Structural Concrete, Model Code 2010, Bulletin 66, (2012)

[11] European Standard, EN 10080, (2005)

[12] E. Cadoni, L. Fenu, D. Forni, Constr. Build. Mat. 35, 399-407 (2012)

[13] E. Cadoni, M. Dotta, D. Forni, N. Tesio, Appl. Mech. Mat. 82, 86-91 (2011)

[14] E. Cadoni, M. Dotta, D. Forni, N. Tesio, Mater. Struct. 1-11 (2014)

[15] N.K. Singh, E. Cadoni, M.K. Singha, N.K. Gupta, J. Eng. Mech-ASCE 139(9), 1197-1206 (2013)

[16] C. Albertini, E. Cadoni, G. Solomos, Philos. Trans. A Math. Phys. Eng. Sci. 372 (2015)

[17] E. Cadoni, M. Dotta, D. Forni, N. Tesio, C. Albertini, Mat. Des. 49, 657-666 (2013)

[18] G.J. Johnson, W.J. Cook, Eng. Fract. Mech. 21-31 (1985)

[19] G.R. Cowper, P.S. Symonds, Div. Appl. Math. Rep. (1957)

[20] D. Asprone, E. Cadoni, A. Prota, ACI Struct. J. 106, 523-529 (2009)

[21] E. Cadoni, M. Dotta, D. Forni, P. Spaetig, J. Nucl. Mat. 414(3), 360-366 (2011)

[22] A. Caverzan, E. Cadoni, M. di Prisco, Int. J. Imp. Engng. 45, 28-38 (2012)

[23] A. Caverzan, E. Cadoni, M. di Prisco, Mech. Mat. 59, 87-109 (2013) 